\title{
Das Verschwinden der Milchstrasse
}

\section{Erhard Taverna}

1. Einmal, im Süden Marokkos, stand ich plötzlich am Abgrund der Nacht. Das Haus lag wenige Schritte hinter mir, es war absolut still und kein Lichtschein zu sehen. Dort oben tat sich unerwartet eine tiefe Schwärze auf, als müsste man in sie hineinfallen. In ihr versanken die kahlen Bergketten, die Palmen und das ganze Dorf. Mir schwindelte, denn ein gewaltiger Sog ging von dieser Tiefe aus, ein Zerren aus bodenlosen Schluchten hinter neblig schimmernde Sternschwaden, ein Ziehen zu den Finsternisgebirgen mit ihren kalt funkelnden Lichttürmen. Es war als hätten sich viele Vorhänge vor einem riesigen Raum geöffnet, und der Himmel schien zum Greifen nahe. Schrecken mischte sich mit Glück, wie vor dem Absprung.

2. Seit den 70er Jahren messen Satelliten regelmässig den terrestrischen Nachthimmel. Das globale Bild dieser Daten deckt sich mit dem Reichtum der Bodenbewohner. Der Lichtabfall aus den Ballungszentren des Nordens verschmutzt die Dunkelheit. Astronomen schlagen Alarm, aber nicht nur sie. Auch Biologen und Medizinforscher weisen auf fatale Folgen hin. Strassenlampen als Massengräber für Insekten zu Lande und zu Wasser entziehen vielen Tierarten die Lebensgrundlage. Zugvögel verlieren die Orientierung, da sie aus den Lichtfallen der grossen Städte nicht mehr herausfinden. Vor allem bei schlechtem Wetter gehen jedes Jahr Tausende zugrunde, weil sie nach stundenlangem Kreisen über unseren Agglomerationen ihre Energien aufbrauchen. Frisch geschlüpfte Seeschildkröten verwechseln den beleuchteten Strand mit dem Meer,

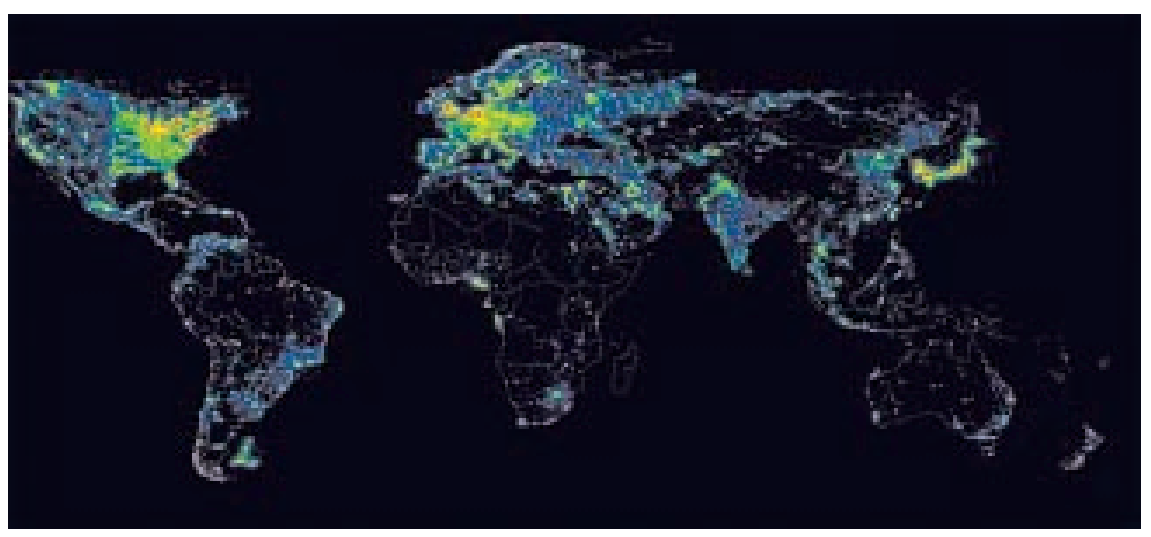

Fischfangflotten leeren mit ihren Lichtködern die Ozeane.

3. Körperliche Auswirkungen auf den Menschen sind noch wenig untersucht. Hinweise mehren sich, dass ein gestörter Melatoninzyklus nicht nur den Schlaf-Wach-Rhythmus, sondern auch andere Hormonaktivitäten beeinflusst. Den grössten Teil seines Lebens verbringt der Mensch in Gebäuden, wo er tags zu wenig und nachts zuviel Licht hat. Die Chronobiologie kann nachweisen, dass die Verschiebung der inneren Uhren einen chronischen Jetlag bewirkt. Über Altersvorgänge, die Funktion des Immunsystems, Zellwachstum, Tumorkrankheiten und viele psychophysiologische Probleme unter Lichteinfluss wird intensiv geforscht. Dass immer mehr Menschen immer weniger Sterne, geschweige denn die Milchstrasse, sehen können, ist ein weiteres Indiz für die globale Umweltzerstörung. Mit unabsehbaren Gesundheitsfolgen.

4. Mit romantischer Gefühlsduselei hat die Sorge um «sky pollution» nichts zu tun. Bereits spricht der Philosoph Ludger Lütkehaus angesichts «der prekären Lage der Nacht» von einem Menschenrecht auf Dunkelheit (und Stille). In den USA kämpft die «International Dark Sky Association» für das Ziel eines möglichst dunklen, von Licht unbehelligten Nachthimmels. Es gibt viele einfache, praktische Massnahmen zur Eindämmung der schätzungsweise zu 70\% überflüssigen Lichtquellen. Als erstes Land hat Tschechien 2002 ein Gesetz gegen die Lichtverschmutzung erlassen. Auch in der Schweiz sollen Scheinwerfer Berge, Bahnhöfe und Reklamen beleuchten. Ein Fall für die einheimischen «Dark Sky»-Freunde. Sie werden zunehmend gehört: Zürich hat einen «Plan Lumière», Kanton Basel-Landschaft gibt einen Prospekt mit Tips heraus, Burgdorf hat als erste Stadt himmelwärts gerichtete Scheinwerfer verboten, im Kanton Luzern werden Skybeamer verzeigt.

Der Galileopreis, die höchste europäische Auszeichnung zum Schutz des Nachthimmels, wurde im Oktober 2004 an «Dark Sky Switzerland» verliehen. Einen medizinischen Förderpreis hätten sie auch verdient. 